\title{
Caught up with Time
}

\author{
George S. Abi Saad ${ }^{\mathrm{a}} \quad$ Khaled M. Musallam $^{\mathrm{a}} \quad$ A. Antoine Kazzi ${ }^{\mathrm{b}}$ Zeina R. Korban ${ }^{\mathrm{a}}$ \\ Ossama M. Reslan ${ }^{a}$ Mustapha Mneimne ${ }^{a}$ \\ Departments of a Surgery, Division of General Surgery, and ${ }^{b}$ Emergency Medicine, American University of Beirut \\ Medical Center, Beirut, Lebanon
}

A 34-year-old male patient, known to be schizophrenic, was brought to our emergency department with a 2day history of sudden-onset hoarseness. The patient had no symptoms of dysphasia, odynophagia, dyspnea, hematemesis or choking, and no previous history of otolaryngological or respiratory disease. Physical examination was unremarkable. The oropharyngeal cavity was clear, and no neck tenderness or subcutaneous emphysema was noted. A neck X-ray was ordered and showed a radiopaque shadow in the proximal esophagus consistent with a wristwatch (fig. 1). Rigid and flexible endoscopy were both attempted under sedation with no success in retrieval. A second attempt with the rigid esophagoscope was done under general anesthesia, but again the foreign body could not be extracted. Measurement revealed that the watch was $18 \mathrm{~cm}$ away from the incisors. Esophagotomy through a left oblique cervical incision was performed (fig. 2a), and the wrist watch was successfully removed (fig. 2b). The postoperative course was smooth, and the control gastrograffin swallow revealed no leak 7 days after the operation. The patient was started on oral feeding and discharged home the next day.

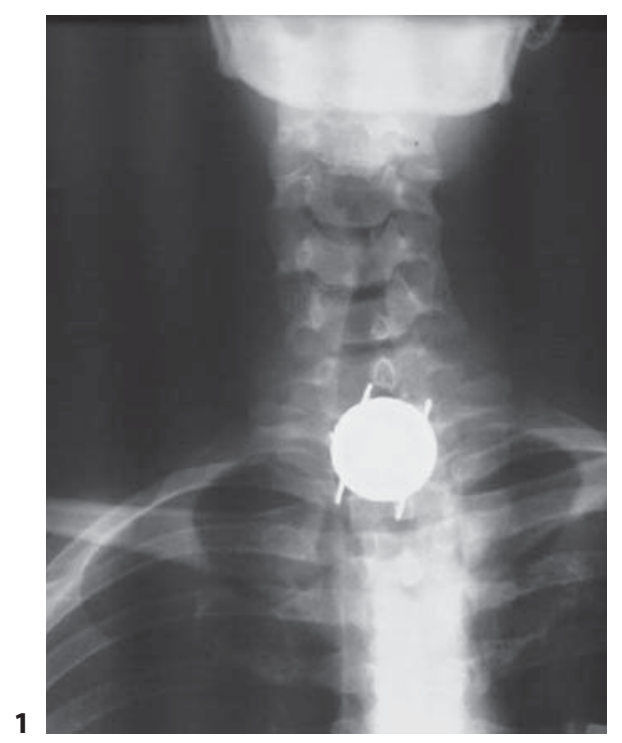

\section{KARGER}

Fax +4161306 1234 E-Mail karger@karger.ch www.karger.com
(C) 2009 S. Karger AG, Basel 0253-4886/09/0261-0024\$26.00/0

Accessible online at:

www.karger.com/dsu
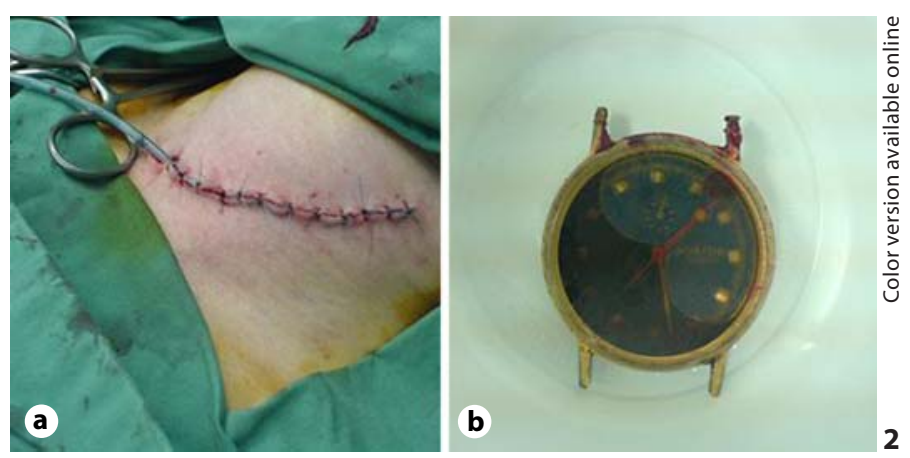

Fig. 1. Neck X-ray showing a radiopaque shadow in the proximal esophagus consistent with a wristwatch.

Fig. 2. a Left oblique cervical incision. b Extracted wristwatch.
George S. Abi Saad, MD

American University of Beirut Medical Center

Division of General Surgery, Department of Surgery

PO Box 11-0236, Riad El Solh 1107 2020, Beirut (Lebanon)

Tel. +961 1350 000, Fax +961 1363 291, E-Mail ga17@aub.edu.lb 